\title{
O impacto da contrarreforma do Estado na política de Atenção Primária à Saúde - APS e no trabalho do assistente social
}

Recebido: 28 jan 2019 Aceito: 10 fev 2019

Autor de correspondência: gabrielacristina.bragabisco@ gmail.com

Conflito de interesses: Os autores declaram não haver nenhum interesse profissional ou pessoal que possa gerar conflito de interesses em relação a este manuscrito.

\author{
${ }^{(1)}$ Faculdade de Ciências Humanas e Sociais, Universidade Estadual Paulista "Júlio de Mesquita \\ Filho" - UNESP, Franca, SP, Brasil.
}

\section{Resumo}

No contexto das transformações societárias, as mudanças no mundo do trabalho afetam tanto a classe trabalhadora, com o crescente retrocesso em relação aos direitos sociais e o trabalho de profissionais que atuam diretamente no desenvolvimento de políticas públicas para a população. Diante do contexto de precarização dos serviços públicos, principalmente na área da saúde, com serviços cada vez mais focalizados e seletivos, o trabalho da(o) assistente social é importante na medida em que contribui para que a população tenha acesso aos serviços de saúde. Na Atenção Primária à Saúde - APS, considerada a porta de entrada dos usuários no Sistema Único de Saúde - SUS, esse trabalho contribui com possibilidades e estratégias de educação e promoção em saúde. Na APS, a(o) assistente social integra as equipes multiprofissionais dos Núcleos de Apoio a Saúde da Família - NASF. Reconhecendo que o trabalho da categoria contribui para ampliar o acesso aos mínimos sociais, a pesquisa tem como pressupostos que o trabalho da(o) assistente social na saúde é relevante e fundamental, na medida em que o Projeto Ético-Político da categoria profissional tem como direção a justiça social e a defesa dos direitos sociais. Além disso, o fortalecimento da APS é fundamental, pois ela é considerada a porta de entrada dos usuários aos serviços de saúde. Objetivo: o objetivo do estudo é analisar o trabalho da/o assistente social diante da contrarreforma na APS da região de Franca/SP; identificar como está estruturado o trabalho da(o) assistente social no NASF; identificar os impactos da contrarreforma da saúde no NASF e refletir a atuação profissional $\mathrm{da}(\mathrm{o})$ assistente social no NASF e a contribuição para o fortalecimento dos princípios da universalidade e integralidade da saúde. Método: para o alcance dos objetivos propostos, o método de estudo adotado é o materialismo histórico dialético, considerando a sua capacidade de explicação da realidade social na perspectiva da totalidade. Além dessa abordagem, a pesquisa qualitativa possibilita uma análise profunda da realidade social, ou seja, que vai além da imediaticidade e da aparência. Com essas duas bases de pesquisa, o estudo está sendo realizado a partir de revisão bibliográfica com autores que discutem o tema da Política de Saúde no Brasil, da APS e do trabalho $\mathrm{da}(\mathrm{o})$ assistente social nessa área. Para compreender os impactos da contrarreforma do Estado, está sendo feito um levantamento dos documentos e 
orientações do Banco Mundial (BM) relacionados à saúde no Brasil, e uma revisão das legislações, normas e portarias que direcionam as ações e a gestão da APS. Após a análise bibliográfica será desenvolvida a pesquisa de campo no âmbito regional, para mapear a realidade de forma mais abrangente. Dessa forma, o estudo terá como universo o NASF dos três municípios com o maior número de habitantes do Departamento Regional de Saúde de Franca (DRS) VIII, do Estado de São Paulo. As cidades selecionadas com o maior número de habitantes foram: Franca, com 318.640 mil habitantes; São Joaquim da Barra, com 46.512 mil habitantes; e Orlândia, com 39.781 mil habitantes. A pesquisa de campo será realizada com assistentes sociais das unidades, equipe de trabalho e usuários atendidos. Com as(os) assistentes sociais serão realizadas entrevista semiestruturada com questões que possibilitem uma apreensão do trabalho profissional na APS, os principais desafios e as principais estratégias de intervenção para o acesso dos usuários aos serviços de saúde. Com a equipe de saúde e os usuários dos serviços, será utilizada a técnica do Grupo Focal, permitindo uma compreensão sobre as práticas, ações e comportamentos de determinado grupo de sujeitos, permitindo diferentes percepções sobre um mesmo tema, caracterizando-se como um espaço plural de debate e reflexões. Resultados: Até o momento foi possível identificar como a APS está sendo impactada diante das atuais transformações societárias. A partir da década de 1980, com o avanço do ideário neoliberal, o Fundo Monetário Internacional - FMI e o BM, passaram a interferir diretamente na área da saúde no Brasil, principalmente no que diz respeito ao financiamento, com orientações econômicas a partir de programas de estabilização econômica e de ajuste estrutural, propondo uma reforma do Estado. A aprovação da Política Nacional de Atenção Básica - PNAB permitiu a revisão de diretrizes e normas para a organização da atenção básica no Brasil, para a Estratégia de Saúde da Família ESF e para o Programa de Agentes Comunitários de Saúde - PACS. Porém, contrariando os princípios e diretrizes fundamentais da atenção básica, no ano de 2017 a PNAB foi revisada e nela foram introduzidas definições que representam um retrocesso em relação aos direitos historicamente conquistados para a APS no Brasil. Um exemplo deste retrocesso, é em relação a cobertura universal dos serviços de atenção básica, na nova PNAB existe uma cobertura relativizada e flexibilizada. A cobertura de $100 \%$ destina-se apenas as áreas de risco e vulnerabilidade social não abrangendo a totalidade da população em territórios distintos, o que representa uma segmentação da APS, refletindo o atendimento dos serviços mínimos, com cobertura focalizada e não em uma perspectiva integral e universal. Além disso existe a flexibilização da cobertura em relação ao tamanho da equipe e tamanho da população, alteração na composição da equipe e carga horária, representando uma precarização do trabalho em saúde. Considerações finais: diante dessa realidade complexa e contraditória, o trabalho $\mathrm{da}(\mathrm{o})$ assistente social na APS por meio do NASF, pode contribuir significativamente para o fortalecimento dos princípios da universalidade e integralidade do atendimento e acesso aos serviços de saúde. Devido a 
importância do trabalho da(o) assistente social na saúde para que as reais necessidades da população sejam atendidas, o estudo sobre essa temática tornase valioso, contribuição com novos questionamentos e com possíveis respostas aos desafios contemporâneos enfrentados pela profissão, consequência dos impactos da contrarreforma do Estado.

Descritores: Sistema Único de Saúde; Atenção Primária à Saúde; Estratégia da Saúde da Família. 